\section{Expectativas sobre a assistência ao parto de mulheres usuárias de uma maternidade pública do Rio de Janeiro, Brasil: os desafios de uma política pública de humanização da assistência}

\author{
Patients' expectations concerning childbirth care \\ at a public maternity hospital in Rio de Janeiro, \\ Brazil: challenges for the humanization of \\ obstetric care
}

Marcos Augusto Bastos Dias 1 Suely Ferreira Deslandes 1

\author{
1 Instituto Fernandes \\ Figueira, Fundação \\ Oswaldo Cruz, \\ Rio de Janeiro, Brasil. \\ Correspondência \\ M. A. B. Dias \\ Instituto Fernandes Figueira, \\ Fundação Oswaldo Cruz. \\ Rua Osório Duque Estrada \\ 74, bloco 2, apto. 701 \\ Rio de Janeiro, $R J$ \\ 22451-170, Brasil. \\ marcosad@centroin.com.br
}

\begin{abstract}
This study analyzes patients' expectations at a public maternity hospital in Rio de Janeiro, Brazil, concerning childbirth care. The methodology was based on a thematic analysis of interviews held during the eighth and ninth months of pregnancy. The study analyzed women's information on humanization of childbirth care, experience pertaining to care received during previous deliveries, their notions of ideal treatment during the current delivery, and attention received from the health care team. The results show that women's expectations focus on three main elements: speedy hospital admission, guaranteed admission to the maternity hospital, and treatment by an attentive and skilled team that cares for the patient's own health and that of her infant. Conflicting information on quality of care in the maternity hospital is a source of additional stress for these women, since in their view quality of care is more a matter of luck than routine institutional management. Based on these expectations, the authors assess the challenges for humanization of childbirth care currently under implementation in the city of Rio de Janeiro.
\end{abstract}

Humanizing Delivery; Maternal-Child Health Services; Prenatal Care

\section{Introdução}

O parto é um evento anunciado e esperado pela gestante e seus familiares, repleto de significados que são (re)construídos dinamicamente na cultura. As mulheres elaboram suas expectativas em relação ao momento do parto a partir de experiências anteriores, de materiais informativos e da televisão, por meio de informações e conversas com outras mulheres e de seu background cultural 1 .

O trabalho de parto é a última etapa antes desse evento de grandes proporções físicas, psicológicas e culturais. Fisiologicamente as últimas horas da gravidez são caracterizadas por dores decorrentes das contrações que ocasionam a dilatação do colo uterino e forçam a saída do bebê pelo canal vaginal. As transformações corporais acontecem de forma rápida, ao contrário daquelas que ocorrem gradualmente durante os meses de gestação. É também quando se dá o início da separação do bebê, um processo psicológico importante para a mulher ${ }^{2}$.

A antropologia médica, desde os fins dos anos 70, tem apontado que o parto por sua riqueza simbólica e por redefinir status sociais e relações pode ser considerado como um rito de passagem ${ }^{3}$, marcando o início de uma série de mudanças no status da mulher em mãe e redimensionando as relações familiares.

Estudos têm demonstrado que dentre as principais expectativas das mulheres em relação 
ao trabalho de parto e parto estão a possibilidade de participação ativa nesses momentos, o autocontrole (durante as contrações) e o controle da situação, além de conhecer o profissional que vai atendê-la, ter segurança acerca do apoio que receberá deste profissional e a expectativa de contar com um acompanhante 1,4,5. Entretanto, as expectativas das mulheres dos estratos médios de renda em relação ao parto mostram-se diferentes daquelas oriundas dos baixos estratos de renda 6. Para aquelas é importante participar do processo, ter controle sobre o mesmo e ser menos submetida à intervenção de tecnologias durante a assistência. Para as mais pobres, o trabalho de parto está associado a uma dor e sofrimento que desejam que termine o mais rapidamente possível com a ajuda da intervenção dos profissionais. Em ambos os grupos, as mulheres demonstram grande preocupação com sua segurança e do bebê 1 .

As futuras mães manifestam ainda sua preocupação com a possibilidade de não reconhecerem os sinais do trabalho de parto e não "ter tempo" de chegar ao hospital. Receiam a duração prolongada desse trabalho de parto e de serem enganadas por um "alarme falso", sendo orientadas a voltar para casa 2 .

Uma das principais expectativas das mulheres ao final da gestação é a intensidade da dor no trabalho de parto. Uma gestante pode não saber o sexo, a cor dos olhos ou dos cabelos de seu bebê, mas sabe quase com certeza que seu trabalho de parto produzirá alguma dor 7 . Domingues et al. 8 , em pesquisa com puérperas usuárias de uma maternidade pública no Município do Rio de Janeiro, relatam que dor e sofrimento foram as imagens mais citadas pelas mulheres quando pensavam no momento do parto.

A introdução de tecnologia médica para aliviar a dor e aumentar a segurança do processo de parturição foram elementos importantes no processo de medicalização do parto e nascimento ${ }^{9}$. Contudo, muitos autores apontam que o uso maciço de tecnologia na assistência ao trabalho de parto e parto levou a uma "desumanização" desta, inclusive com riscos de iatrogenia para as gestantes e seus bebês 3,10,11. As propostas de humanização da assistência ao parto compreendem esse evento como sendo de natureza fisiológica e cultural, momento no qual a mulher necessitaria mais de suporte psico-afetivo do que de intervenções médicas de questionável eficácia $12,13,14,15$

No Município do Rio de Janeiro, a Secretaria Municipal de Saúde (SMS/RJ) vem há vários anos implantando ações de humanização da assistência ao parto 16. Entretanto, existe pouca informação disponível sobre as expectativas das usuárias de maternidades públicas, o que impede um planejamento e orientação de estratégias para promover um atendimento que esteja mais consoante com suas necessidades e demandas.

O objetivo deste trabalho é conhecer as informações que as gestantes possuem sobre a humanização da assistência ao parto, a experiência de atendimento em parto(s) anterior(es) e suas expectativas, como usuárias das maternidades públicas do Município do Rio de Janeiro, em relação ao atendimento ao parto que esperam receber na gravidez atual.

\section{Metodologia}

Trata-se de um estudo qualitativo que procurou explorar as expectativas de gestantes sobre o atendimento ao parto da sua gestação atual e a avaliação que fazem da atenção recebida em partos anteriores. A entrevista foi a técnica empregada para a construção dos dados. Foram realizadas vinte e duas entrevistas semi-estruturadas, gravadas e transcritas de maneira literal, embora, para efeitos de exposição tenham sido realizadas pequenas correções, com o objetivo de tornar mais claras as idéias das depoentes. Essas entrevistas foram realizadas no mesmo serviço onde eram feitas as consultas de pré-natal e a atividade de "sala de espera das gestantes".

Considerando-se a temática trabalhada, uma vez que as questões de gênero poderiam interferir na interação durante a entrevista e, conseqüentemente, nas repostas das mulheres entrevistadas, optamos por recorrer ao apoio de uma pesquisadora auxiliar que realizou todas as entrevistas com as mulheres 17 .

\section{Sujeitos da pesquisa}

Foram recrutadas para a pesquisa as grávidas entre o oitavo e o nono meses da gestação, época em que geralmente as mulheres já estão mais sensíveis às questões relativas ao nascimento do bebê. Todas eram usuárias de uma maternidade da rede própria da SMS/RJ. Optamos por entrevistar gestantes que já tivessem a experiência de pelo menos um parto vaginal anterior, o que lhes garantiria maiores informações sobre o processo de assistência ao trabalho de parto e parto. Essa opção deveu-se também ao fato dessas mulheres terem maior possibilidade de novo parto vaginal nesta gestação e de comparação da assistência recebida nos dois momentos.

Entre as mulheres que realizaram a entrevista, apenas uma não morava com o companheiro naquele momento. $\mathrm{O}$ grupo de entrevistadas era predominantemente de mulheres de 20 a 30 anos 
(14 mulheres), com até oito anos de estudo (16 depoentes) e renda familiar na faixa de até três salários mínimos (14 mulheres).

\section{Análise dos dados}

A análise dos depoimentos buscou distinguir nas mensagens seus conteúdos latentes e manifestos, interpretando seus significados, articulando de forma hermenêutica o conteúdo social da produção destes relatos 18 . Foi procedida uma adaptação dos princípios da Análise de Conteúdo priorizando a técnica da Análise Temática 19.

Na fase de pré-análise das entrevistas foram levantadas questões e formuladas hipóteses. Num segundo momento foram categorizados os temas centrais, tais como conhecimento sobre humanização, experiência de parto anterior e expectativas de atendimento ao parto, sendo então destacadas as categorias êmicas. A categoria "ter sorte" surgiu como a síntese nucleadora das expectativas das entrevistadas quanto ao atendimento. Como corroboram Hammersley \& Atkinson 20 , nessa fase, à medida que o processo de separação e comparação dos dados vai se dando, o relacionamento mútuo e as estruturas internas das categorias vão ficando dispostas de maneira mais clara. Como forma de aprofundar a análise das relações entre os fenômenos estudados utilizamos a triangulação das fontes de dados, checando as informações obtidas com o trabalho etnográfico que estava sendo realizado pelo pesquisador na mesma maternidade. A triangulação, como ressaltam esses autores, envolve a comparação dos dados relativos a um mesmo fenômeno, mas provenientes de diferentes fases do trabalho de campo, de diferentes tempos e métodos da pesquisa ou de diferentes participantes. O que está envolvido na triangulação não é apenas checar se os dados são válidos, mas descobrir quais inferências daqueles dados são válidas. Finalmente, foi tecida a articulação entre as categorias empíricas e o quadro teórico.

\section{Resultados e discussão}

\section{Humanização um conceito desconhecido}

O conceito de humanização da assistência ao parto era desconhecido para as mulheres entrevistadas.

“Não. Nunca (...) nunca ouvi falar sobre isso. É a primeira vez. Estou ouvindo agora falar" (Entrevista 8).

Após informadas sobre o que consistia a proposta de humanização do parto, as mulheres não reavaliam mais negativamente a assistência que receberam nas gestações anteriores, mas ressaltam que tiveram muito pouca informação durante todo o processo. Green et al. 1, em pesquisa na Inglaterra sobre expectativas e experiências de 747 gestantes com o nascimento, encontraram que a grande maioria delas gostaria de receber toda a informação possível sobre trabalho de parto, independente do nível educacional ou condições econômicas. Nossa pesquisa verifica que, seja durante a admissão ao hospital, seja durante o atendimento ao trabalho de parto e parto ou no cuidado durante a permanência no alojamento conjunto, as mulheres recebem pouca ou nenhuma informação sobre os procedimentos a que estão sendo submetidas, a evolução do trabalho de parto ou os cuidados que devem ter com sua saúde após a alta.

Apesar de diversas ações da SMS/RJ nessa área, entre elas uma resolução que garanta o direito da mulher a um acompanhante no parto e da produção de um cartaz para divulgar esta possibilidade, as gestantes entrevistadas parecem não ter sido alcançadas pelo esforço de divulgação da política de humanização da assistência.

\section{A experiência anterior \\ de assistência ao parto}

A avaliação das mulheres em relação ao atendimento recebido em seu(s) parto(s) anterior(es) foi no geral positiva, coincidindo com os achados de Leal et al. 21 em pesquisa com puérperas no Município do Rio de Janeiro. Nossas entrevistas revelam que a satisfação das mulheres estava associada principalmente a conseguir vaga para internação, ser atendida sem demora na admissão e à rapidez do nascimento do bebê. Esses elementos tornam-se novamente presentes e são reiterados nas expectativas relacionadas ao parto atual.

Se por um lado algumas mulheres afirmaram que foram bem atendidas, por outro, cabe ressaltar que em nenhum momento os serviços foram alvo de elogios. Na verdade, a satisfação parece ser sempre pontual pela atuação de algum profissional ou porque o nascimento foi rápido, com poucas dores e não aconteceu nenhuma complicação.

Apesar de quase a totalidade dos nascimentos no Município do Rio de Janeiro serem hospitalares e embora muitas maternidades trabalhem com leitos extras, o principal problema é que muitas gestantes precisam se deslocar à procura de uma vaga ${ }^{21}$. As mulheres realizam uma verdadeira peregrinação porque os leitos obstétricos não são distribuídos de forma homogênea pela cidade e o acesso a algumas unidades é mais difícil. Além disso, como vimos na pesquisa, as 
mulheres também tentam precariamente garantir uma "certa escolha" já que algumas unidades têm melhor fama (as unidades próprias do município) junto à população do que outras (os leitos conveniados pelo SUS), dando o contexto dessa peregrinação.

Os profissionais das maternidades próprias da rede pública municipal têm com freqüência de transferir parturientes para outras unidades. Como nem sempre se responsabilizam por conseguir uma vaga antes dos encaminhamentos, muitas vezes os mesmos são feitos de forma verbal e as mulheres não possuem nenhuma garantia de obtenção da vaga. No período 2000/2001, não conseguiram ser atendidas no primeiro hospital 23,9\% das mulheres no Município do Rio de Janeiro ${ }^{21}$. Giffin et al. 22, num estudo sobre fatores associados à realização de cesárea e qualidade da atenção ao parto em duas maternidades no $\mathrm{Mu}$ nicípio do Rio de Janeiro, encontraram que cerca de $40 \%$ das mulheres não foram internadas no primeiro hospital que procuraram. Consoante a tais dados, verificamos que a maior angústia para as gestantes entrevistadas é a impossibilidade de ter garantida uma referência certa para o parto antes do início do trabalho de parto.

A atenção oferecida pela equipe durante o trabalho de parto é outro importante fator na satisfação da mulher com o atendimento recebido ${ }^{8}$. Quando um membro da equipe de saúde faz um vínculo com a parturiente ela se sente acolhida e cuidada, mesmo que esse profissional não permaneça com ela durante todo o tempo. Em nosso estudo, a presença de um profissional (geralmente de enfermagem) que deu algum tipo de atenção durante o trabalho de parto, associada à ausência de complicações com a mulher ou com o bebê foi apontada como motivo para satisfação em relação à assistência ao parto anterior. Esses aspectos são evidentes no debate acerca da satisfação de usuários nos serviços públicos, dado o baixo patamar de direitos a que têm acesso 23,24.

A satisfação da mulher também pode ser resultado de uma comparação entre o tratamento que recebeu e o relato que outras mulheres fazem de suas experiências anteriores. Terem sido atendidas em hospitais públicos parece diminuir o nível de suas exigências em relação ao que poderia ser considerado um atendimento de qualidade. Em um hospital público, de forma geral, as mulheres não esperam receber um tratamento mais individualizado ou uma atenção mais carinhosa mesmo no momento do parto, como enfatizam: "porque é muito difícil nos hospitais públicos a gente ser bem tratada como a gente deve ser" (Entrevista 9).

No geral, as histórias de atendimento nesses hospitais estão permeadas por relatos de vio- lências institucionais de várias formas 23,25. Os relatos de nossas entrevistadas revelam que a demora no atendimento, o abandono no leito, a proibição de um acompanhante e em especial a violência verbal são situações vivenciadas pelas mulheres. $\mathrm{O}$ fato de não ter sofrido nenhuma situação de violência faz com que, por comparação, o cuidado que recebeu seja definido como um bom atendimento. Foram diversas as falas das mulheres que afirmam que foram bem atendidas porque não foram maltratadas, indicando que esta situação pode ser rotineira para as usuárias dos serviços públicos.

"Com tudo que eu escuto falar, pelo o que eu vejo com outras pessoas, eu tive um atendimento excelente, por ser o hospital público, entendeu?" (Entrevista 6).

Algumas entrevistadas explicam a violência perpetrada pelos profissionais como uma reação à gestante gritar ou fazer "escândalo" por conta das dores nas contrações durante o trabalho de parto, o que não seria considerado um comportamento adequado pela equipe de saúde.

"Tem gente que chega no hospital faz escândalo (...) e eles deixam mesmo para lá, não é? Vão pegar quem está mais quieta. Geralmente acontece isso, entendeu? Então a gente fica assustada, com certeza fica" (Entrevista 3 ).

Como se vê, uma das preocupações das gestantes demarcadas na literatura tem relação com o comportamento que terão frente à dor no trabalho de parto. O medo de perder o controle está associado às punições que serão impostas pelos profissionais frente ao seu "mau comportamento" 23 . As mulheres que reclamaram do atendimento no parto anterior, apontam ainda como falha do serviço onde foram atendidas ficarem "abandonada" no pré-parto durante o trabalho de parto, ficando sem atenção durante o período em que passavam pelas dores das contrações uterinas.

Os profissionais raramente se identificam ou tratam a mulher pelo nome, apenas avaliam as gestantes de tempos em tempos, o que lhes dá a sensação de abandono. Também apontam como falhas da assistência ter sofrido violência por parte da equipe, seja ela verbal ou mesmo física na forma de toques vaginais demorados e dolorosos, ou outras intervenções a que foram submetidas sem que tenham tido qualquer informação sobre o que estava acontecendo.

Como corroboram os estudos de Domingues et al. 8 e Green et al. 1, nossas entrevistadas indicam que a demora no nascimento do bebê que a fez "sofrer" durante horas, e/ou a ocorrência de alguma complicação com o mesmo também interferem negativamente na sua avaliação sobre a qualidade da assistência. Uma gestante rela- 
ta sua experiência anterior, apontando todas as falhas que identificou no atendimento que recebeu: “Ah! Foi horrível! (...) primeiro eu cheguei num hospital onde eu não tive vaga porque aparelhos estavam quebrados é (...) eu tinha quinze anos, (...) fui transferida de ambulância. Até aî foi ótimo. (...) eles não me deixaram com acompanhante, sendo que eu tinha direito (...) eu fui internada sete e pouca e só fui ter meu filho cinco horas da tarde. E demorou muito. Deixam as pessoas jogadas. O médico era muito ignorante" (Entrevista 9).

\section{A gestação atual, o parto idealizado} e a realidade de ser usuária

Apenas três das 22 mulheres entrevistadas planejaram sua gestação atual. Algumas tentaram interrompê-la, mas não tendo sucesso nesta tentativa conformaram-se e deixaram-na evoluir. Em outras falas percebemos a importância do papel da maternidade, na formação de novos vínculos, quando em um novo relacionamento o parceiro atual não tem filhos, e mesmo não desejando, a mulher engravida para dar ao parceiro o filho por ele desejado.

"Não foi planejada, não. Eu não queria não. Mas já que aconteceu (...) não é? (...) Ele não tem filho, a mãe dele não tem neto (...) é o primeiro neto, primeiro filho. Mas que eu queria, não queria não (...) Fiquei um pouquinho deprimida (...) Pensei até em tirar (...) tomar alguma coisa. Só que a minha sogra foi conversando comigo, e ele também foi contra. Se você quiser você vai se virar com seu dinheiro que o meu não vou te dar nada" (Entrevista 10).

Todas as mulheres referiram ter o apoio do companheiro ou da família durante esta gestação. Avaliam que esse suporte é importante porque consideram que a gestação é um momento de fragilidade emocional e física da mulher. $\mathrm{O}$ apoio se manifestava de diversas formas, seja por um comportamento mais afetivo, pela ajuda no cuidado com a casa e com outros filhos, ou ajuda material com o enxoval ou alimentos. Entretanto, como se sabe, a presença do companheiro durante as consultas de pré-natal é rara. Em especial devido ao horário de trabalho dos homens que coincide com os horários das consultas. A ausência destes acaba criando um ambiente praticamente só de mulheres e crianças, o que por sua vez acaba inibindo a presença masculina.

Paradoxalmente são poucas as iniciativas para incentivar que os parceiros das gestantes participem das consultas de pré-natal, embora o Ministério da Saúde aponte a necessidade de acolher a mulher e aproveitar a oportunidade da gestação para discutir com ela e a família questões de saú- de. Além da troca de informações facilitar a participação do companheiro, também a assistência pré-natal é apontada como o primeiro passo para o parto e nascimento humanizados 26 .

Assim, uma vez assumida a gestação, a mulher tem diante de si inúmeras variáveis para a busca de um determinado serviço de saúde para realizar o acompanhamento. A principal razão apontada nas entrevistas para realizar o pré-natal e o atendimento ao parto na maternidade estudada foi a proximidade de sua residência. As dificuldades de locomoção dessa clientela são importantes, em especial durante o período noturno quando são menores as ofertas de transporte público. Cerca de $25 \%$ das gestantes que tiveram seus partos em maternidades municipais ou federais chegaram às mesmas em transporte coletivo ou a pé, segundo achados de Leal et al. ${ }^{21}$. Também influenciou a opção pela maternidade estudada o fato de já terem sido atendidas lá anteriormente e aprovado, de alguma forma, a assistência recebida.

O pré-natal na maternidade estudada, funciona de forma bastante regionalizada. As inscrições são abertas periodicamente e basta a mulher apresentar um comprovante de residência na área para se inscrever. Cientes dessa exigência, elas usam como subterfúgio para conseguir o atendimento apresentar no ambulatório o comprovante de endereço do trabalho do companheiro ou de amigos e parentes. As pacientes referidas por outras instituições, como a maternidade de risco da área que encaminha pacientes de baixo risco, também não relataram dificuldade de acesso.

Em geral estão satisfeitas com a assistência pré-natal recebida e valorizam bastante o fato de os medicamentos prescritos pelos profissionais serem entregues de forma gratuita pela Instituição. Receber informações sobre a gestação e o parto, poder falar de sua experiência como gestante com o profissional e tirar dúvidas foram também apontados como motivos de satisfação deste atendimento atual.

As reclamações da assistência pré-natal baseiam-se na atenção prestada por um ou outro profissional que oferece pouca informação ou oportunidade para que a mulher tire suas dúvidas durante a consulta. Também é motivo de insatisfação a demora para o atendimento, uma vez que todas são agendadas no mesmo horário e atendidas por ordem de chegada. A espera pela consulta pode ser de até três horas.

“...Outra coisa que eu acho horrível é você ter que chegar aqui dez e meia da manhã para entregar o cartão, onze horas pesar e esperar de onze até uma hora da tarde para doutora começar a atender. É um abuso isso conosco, eu acho, isso éo meu modo de pensar" (Entrevista 3). 
Quando pergutamos sobre as expectativas em relação ao parto vindouro, não foi fácil conseguir por parte das mulheres uma abstração tal que pudessem idealizar este momento sem pensar nos dados do seu cotidiano de usuárias da maternidade e de outros serviços públicos. Elas também não conhecem alternativas ao atendimento tradicional oferecido pela maternidade e o que poderiam demandar se tivessem acesso a outros cuidados oferecidos em serviços diferenciados.

Não faz parte das possibilidades aventadas pelas gestantes ter qualquer controle sobre as questões relativas aos cuidados que receberão. Predomina a concepção de que o trabalho de parto e o parto serão conduzidos exclusivamente pelos profissionais de saúde, não cabendo a elas nenhum direito de opinar ou manifestar seus desejos em relação à assistência.

Como Hundley \& Ryan 27 apontam, os serviços oferecidos pelo sistema de saúde influenciam as preferências das mulheres sobre os aspectos do cuidado no trabalho de parto que adotarão. $\mathrm{O}$ conhecimento, pela usuária, das diferentes alternativas disponibilizadas pelo hospital influencia sua preferência, e tem implicações na decisão de adotar ou não tecnologias de cuidado com as quais não está familiarizada.

Como já apontado na avaliação do parto anterior, os elementos que constituem o atendimento ideal, para esse grupo, são uma recepção rápida no momento da chegada à maternidade, e a atenção de uma equipe educada, cuidadosa e paciente no cuidado durante o trabalho de parto e parto. Tais predicados da equipe são importantes porque as mulheres desejam que os profissionais sejam compreensivos nesse momento em que elas estão com dores e amedrontadas. A competência no atendimento com ela própria e com o bebê, "uma obrigação deles", também faz parte desse cenário imaginado pelas mulheres.

"Que eu seja bem tratada, corra tudo bem, que minha filha seja bem atendida e eu também. Que não aconteça nenhum tipo de erro médico. Só. Só isso. O básico, não é? O necessário" (Entrevista 2).

O trabalho de parto idealizado deve ser também rápido porque o medo da dor e de uma evolução mais demorada, que exija mais cuidado dos profissionais e mais desgaste para a mulher, é uma questão importante para elas. Como que descrentes da real possibilidade da presença de um acompanhante no momento do trabalho de parto e do parto, apenas uma mulher idealizou sua internação com a presença do companheiro, embora todas tenham falado da importância do apoio do mesmo durante a gestação.

A possibilidade de ter um acompanhante durante o trabalho de parto e parto é uma situação nova para as mulheres que realizam pré-natal no serviço estudado. Em suas experiências de parto anterior nenhuma teve a possibilidade de ter um acompanhante, mesmo quando teria essa prerrogativa assegurada por lei como no caso de uma adolescente, cujo direito está garantido no Estatuto da Criança e do Adolescente desde 1990.

$\mathrm{O}$ direito de ter um acompanhante durante o trabalho de parto e no momento do parto já é há muito tempo uma possibilidade para as mulheres que utilizavam os serviços privados de saúde. O Rio de Janeiro foi o primeiro município no Brasil que regulamentou a presença de acompanhantes no trabalho de parto e parto nas maternidades próprias da sua rede. Embora no início de sua implantação houvesse muita resistência dos profissionais em garantir a presença do acompanhante (e esta resistência persiste), atualmente para cerca de $40 \%$ das usuárias da rede municipal ela tem sido garantida, ao passo que esta possibilidade só foi possível para cerca de 6\% das usuárias dos outros serviços do SUS 21. O mesmo estudo 21 aponta que, por outro lado, o acompanhante pode estar presente no trabalho de parto e parto de $67,7 \%$ das usuárias dos serviços privados de saúde. Em contrapartida, a possibilidade da presença do acompanhante tem criado uma nova expectativa não apenas nas mulheres, mas também em seus companheiros: "Espero que nesse parto eu possa ter acompanhante (...) eu quero ter e ele também quer. (...) Ele quer assistir o parto. E isso aí eu já não sei se eles vão deixar. Não sei mesmo" (Entrevista 12).

Ressalta-se, entretanto, que ao se adotar uma perspectiva de humanização da assistência de forma normativa, este modelo corre o risco de provocar a imposição da presença do companheiro. Para Tornquist 6, a visão da presença do homem no espaço do trabalho de parto e parto é diferente entre as famílias de classes médias e de classes populares, que podem preferir a presença de uma acompanhante do sexo feminino, pois esta pode ser tida como uma "tarefa de mulheres".

O principal dado da realidade que interfere com a tentativa de idealização das mulheres é o fato de que apesar de realizarem o pré-natal na maternidade, isto não lhes garante a vaga para a internação no momento do parto.

"Como é que eu imagino? Eu nem imagino. Espero que aconteça. (...) Aí eu entro (...) chega pra mim e fala: 'Você vai ficar'. Oh! Que alegria! Tem coisa melhor? Do que chegar aqui e falar que vai ficar?" (Entrevista 10).

O parto idealizado para enfrentar essa situação é, portanto, aquele que evolui de forma rápida, possibilitando que ao chegar à maternidade a mulher tenha de ser internada independente da existência de vaga. A estratégia pensada para driblar a possibilidade da falta de vagas é ficar 
em casa “enquanto agüentar". Referida por várias mulheres, ela é utilizada porque sabem que não haveria tempo hábil para a transferência para outra unidade se chegarem à maternidade com dilatação avançada. Aguardar em casa também serviria para evitar que tenham de se deslocar até a maternidade e depois voltarem porque "ainda não estava na hora”. Enfim, o ideal é, portanto, um atendimento que garante apenas o mínimo que seus direitos de cidadã demandam, tão somente uma referência concreta para o momento do parto e um atendimento digno e seguro para si e seu bebê.

Assim, o que de mais concreto conseguem apontar são as estratégias que adotarão, seja no sentido de garantir vaga na internação, seja no sentido de garantir que sejam bem tratadas. Apenas duas das mulheres apontaram o desejo de realizar uma cesariana para que as questões relativas ao atendimento e ao trabalho de parto fossem minimizadas (mais rápida, garantia de internação), mas tal possibilidade é logo afastada porque a vantagem do parto normal parece prevalecer, uma vez que o "sofrimento é só naquela hora" (Entrevista 1).

A idéia de sorte circunda o parto que as mulheres idealizam, ou que imaginam quando confrontado com os dados da realidade. Ela está tão presente nas falas porque as mulheres identificam enormes diferenças nos relatos dos atendimentos oferecidos por uma mesma unidade de saúde. Em um determinado atendimento os profissionais foram educados e atenciosos agradando a usuária, e em outro foram indiferentes e grosseiros e a mulher se sentiu mal tratada. É, portanto, a "sorte" que vai determinar a possibilidade de ser atendida rapidamente e de conseguir uma vaga no momento da internação, superando aí o primeiro medo.

“Tomara que seja aqui né, porque (...) se eu tiver sorte de ter aqui tudo bem, se tiver (...) se for noutro lugar (...) né, tudo bem" (Entrevista 8).

E é também uma questão de "sorte" que uma vez internada ela seja atendida por uma boa equipe no plantão, receba atenção e tenha um tratamento educado, amigável e tecnicamente competente.

"Bom aí (...) é difícil eu imaginar. Porque aqui depende muito do médico. Depende (...) tudo depende do plantão que você pega. Eu posso ter um plantão bom, como também não pode" (Entrevista 15).

A incerteza sobre quando e como o trabalho de parto e parto vão acontecer são suficientes parar trazer ansiedade para as gestantes. Entretanto, a insegurança ocasionada pela total ingovernabilidade das usuárias do serviço público sobre seu atendimento, traz para esse momento elementos que dificultam sobremaneira a possibilidade da vivência prazerosa desse acontecimento.

\section{Conclusões}

As mulheres não conhecem a proposta de humanização da assistência ao parto ou mesmo a política municipal de saúde que engloba seus preceitos. A possibilidade de ter um acompanhante é a única inovação que algumas conhecem dentre os cuidados tradicionais oferecidos pelas maternidades na atenção ao parto. Sem as informações necessárias sobre as diferentes formas de cuidado e uma possibilidade real de opção resta, a essas usuárias, apenas a conformidade com o cuidado "tradicional" oferecido. É praticamente impossível, portanto, para a mulher, construir um plano de parto com as opções de um atendimento mais humanizado a menos que os profissionais, durante o acompanhamento prénatal, estabeleçam uma relação diferente com as clientes. Uma relação menos assimétrica em que sejam discutidas a proposta de atendimento, a importância do protagonismo da mulher nesses eventos e disponibilizada as informações para uma participação efetiva. Ampliar o poder de escolha das usuárias não é, entretanto, uma característica do modelo de atenção medicalizado de nossas maternidades ou serviços de pré-natal. $\mathrm{O}$ maior envolvimento das mulheres pode ser uma forma importante de modificar a visão do que é aceito e do que é importante nas tecnologias de cuidados oferecidas pelos serviços de saúde, facilitando a adoção de mudanças.

A importância do apoio do parceiro e da família na gestação referida pelas mulheres, aponta a necessidade de uma estratégia para que os serviços de pré-natal possam incluí-los neste atendimento.

A experiência do parto anterior e as informações obtidas com as outras gestantes atendidas são as bases da construção de sua expectativa da assistência ao parto atual. No cenário em que trabalham planejando seu atendimento, as mulheres esperam minimamente por um conjunto "básico" de ações que garantam o parto em condições de segurança para elas e seus bebês. Ter vaga na hora em que chega à maternidade, ser recebida com educação e um atendimento tecnicamente competente para ela e o bebê são os principais componentes deste conjunto elementar de expectativas.

Nesse sentido, é fundamental que uma política de humanização da assistência tenha como preceito "básico" um sistema de referência que garanta a vaga para o parto desde o momento em que a mulher inicia a gravidez. A insegurança 
produzida pela incerteza de ter uma vaga para o parto e a possibilidade de ter de, por meios próprios, peregrinar em busca da mesma é uma condição desumana. Diante da expectativa da falta de vaga, a alternativa encontrada pelas mulheres de retardar ao máximo a ida à maternidade para não ter tempo de ser transferida, pode trazer riscos para elas e para os bebês. Entretanto, essa opção é a única dentro de sua governabilidade, pois postergar a ida para a maternidade enquanto julgar seguro pode evitar uma transferência indesejada para outra unidade.

As histórias contraditórias sobre a qualidade do atendimento provocam a desconfiança das mulheres nos serviços públicos de saúde. Nesse sentido, o acolhimento com uma escuta atenta e o tratamento respeitoso e educado por parte dos profissionais de saúde surgem como parte inicial da solução para melhorar as expectativas das mulheres. Uma nova relação profissional de saúde/clientela, pautada nesses preceitos pode aumentar a confiança das usuárias nas unidades. Quiçá as mulheres poderão conceber que um bom atendimento não é uma questão de "sorte",

\section{Resumo}

Analisamos as expectativas de gestantes, usuárias de uma maternidade pública no Município do Rio de Janeiro, Brasil, sobre a assistência que receberam no parto e a avaliação que fazem do atendimento recebido em partos anteriores. A metodologia pautou-se pela análise temática de entrevistas realizadas entre o oitavo e o nono mês de gravidez. Foram analisadas informações das mulheres sobre humanização da assistência ao parto, experiências relativas à assistência recebida em parto(s) anterior(es), seu ideal de atendimento ao parto eminente e sobre a atenção da equipe de saúde. Os resultados mostram que as expectativas estão centradas em três elementos principais: admissão rápida na internação, garantia de vaga na maternidade e o atendimento por uma equipe atenciosa $e$ competente que cuide de sua saúde e do seu bebê. As informações discordantes sobre a qualidade da assistência na maternidade trazem para essas mulheres uma tensão a mais nesse momento já que, a seu ver, a qualidade do cuidado dependerá mais de sorte do que da rotina institucional. A partir dessas expectativas, os autores avaliam os desafios da política de humanização da assistência ao parto em implantação nesse município.

Parto Humanizado; Serviços de Saúde Materno-Infantil; Cuidado Pré-Natal mas uma rotina do serviço e um direito que ela pode exigir.

A discussão sobre os modelos de assistência ao parto e sobre sua excessiva medicalização, parece ser uma questão apenas para as mulheres de maior nível econômico e cultural. Embora sejam nesses estratos sociais que se verificam as maiores taxas de cesariana sem indicação clínica, é crescente o movimento que essas mulheres fazem no sentido de ter maior controle sobre seu parto. $\mathrm{O}$ direito de discutir com os profissionais de saúde seu plano de parto e a maneira como desejam dar à luz, não fazem parte do cotidiano das mulheres que pertencem às camadas populares. Cresce, portanto, a importância de uma política de humanização da assistência ao parto que possa ao atingir as mulheres das camadas menos favorecidas ampliar seus direitos de usuárias dos serviços de saúde. Uma política que possibilite às mulheres vivenciar, nas maternidades públicas, esses momentos não apenas como uma questão de saúde, mas também como um acontecimento social e afetivo que marca profundamente seus protagonistas.

\section{Colaboradores}

M. A. B. Dias realizou a pesquisa e escreveu o texto em parceria com S. F. Deslandes. 


\section{Referências}

1. Green JM, Coupland VA, Kitzinger JV. Great expectations. A prospective study of women's expectations and experiences of childbirth. Cheshire: Books for Midwives Press; 1988.

2. Maldonado MTP. Psicologia da gravidez: parto e puerpério. Petrópolis. Editora Vozes; 1984.

3. Davis-Floyd RE. The rituals of American hospital birth. In: McCurdy D, editor. Conformity and conflict: readings in cultural anthropology. New York: Harper Collins; 1994. p. 323-40.

4. Green JM, Baston HA. Feeling in control during labor: concepts, correlates and consequences. Birth 2003, 30:235-47.

5. Gibbins J, Thomson AM. Women's expectations and experience of childbirth. Midwifery 2001, 17:302-13.

6. Tornquist CS. Paradoxos da humanização em uma maternidade no Brasil. Cad Saúde Pública 2003; 19 Suppl 2:S419-27.

7. Lieberman AB. Easing labor pain: the complete guide to a more comfortable and rewarding birth Boston: Harvard Common Press; 1992.

8. Domingues RMSM, Santos EM, Leal MC. Aspectos da satisfação das mulheres com a assistência ao parto: contribuição para o debate. Cad Saúde Pública 2004; 20 Suppl 1:S52-62.

9. Wagner M. Pursuing the birth machine. The search for appropriate birth technology. Camperdown: ACE Graphics; 1994.

10. Ministério da Saúde. Parto, aborto e puerpério: assistência humanizada à mulher. Brasília: Ministério da Saúde; 2001.

11. Martin E. The woman in the body. Boston: Beacon Press; 1987.

12. Rede pela Humanização do Parto e Nascimento. Carta de Campinas. http://www.rehuna org.br/images/stories/documentos/carta\%20de \%20campinas.doc (acessado em 17/Ago/2006).

13. Rede pela Humanização do Parto e Nascimento. Carta de Fortaleza. http://www.rehuna.org $\mathrm{br} /$ images/stories/documentos/carta\%20de $\% 20$ fortaleza.doc (acessado em 17/Ago/2006).

14. World Health Organization. Appropriate technology for birth. Lancet 1985; 2:436-7.

15. World Health Organization. Care in normal birth: a practical guide. Geneva: World Health Organization; 1996

16. Boaretto MC. Avaliação da Política de Humanização ao Parto e Nascimento no Município do Rio de Janeiro [Dissertação de Mestrado]. Rio de Janeiro: Escola Nacional de Saúde Pública, Fundação Oswaldo Cruz; 2003.
17. Fontana A, Frey JH. The interview. From structured questions to negotiated text. In: Denzin NK, Lincoln YS, editors. Handbook of qualitative research. London: Sage Publications; 2000. p. 645-72.

18. Thompson JB. Ideologia e cultura moderna: teoria social crítica na era dos meios de comunicação em massa. Petrópolis: Editora Vozes; 1998.

19. Bauer MW. Análise de conteúdo clássica: uma revisão. In: Bauer MW, Gaskell G, organizadores. Pesquisa qualitativa com texto, imagem e som. Petrópolis: Editora Vozes; 2002. p. 189-217.

20. Hammersley M, Atkinson P. Ethnography: principles and practice. $2^{\text {nd }}$ Ed. London/New York: Routledge; 1995.

21. Leal MC, Gama SGN, Campos MR, Cavalini LT, Garbayo LS, Brasil CLP, et al. Fatores associados à morbi-mortalidade perinatal em uma amostra de maternidades públicas e privadas do Município do Rio de Janeiro, 1999-2001. Cad Saúde Pública 2004; 20 Suppl 1:520-33.

22. Giffin K, D'Orsi E, Reis AC, Barbosa GP. Fatores associados à realização de cesárea e qualidade da atenção ao parto em duas maternidades do Rio de Janeiro - sumário de resultados. Rio de Janeiro: Escola Nacional de Saúde Pública, Fundação Oswaldo Cruz; 2000

23. Hotimsky SN, Rattner D, Venancio SI, Bógus CM, Miranda MM. O parto como eu vejo... ou como eu o desejo? Expectativas de gestantes, usuárias do SUS, acerca do parto e da assistência obstétrica. Cad Saúde Pública 2002; 18:1303-11.

24. Campos TP, Carvalho, MS. Assistência ao parto no Município do Rio de Janeiro: perfil das maternidades e o acesso da clientela. Cad Saúde Pública 2000; 16:411-20.

25. D'Oliveira AFPL. Violência institucional - o caso da assistência obstétrica. In: Anais do 2o Seminário sobre Nascimento e Parto no Rio de Janeiro. Rio de Janeiro: Secretaria Municipal de Saúde do Rio de Janeiro; 1997. p. 14-6.

26. Ministério da Saúde. Assistência pré-natal. Manual técnico. Brasília: Ministério da Saúde; 2000.

27. Hundley V, Ryan M. Are women's expectations and preferences for intrapartum care affected by the model of care on offer? BJOG 2004; 111:550-60.

Recebido em 23/Set/2005

Aprovado em 27/Abr/2006 